\title{
Alberto Magno sobre imaginación y fantasía'
}

\author{
Jörg Alejandro Tellkamp \\ Universidad Panamericana
}

The present article presents a Spanish translation of Albert the Great's theory of imagination (imagination) and fantasy (phantasia). The corresponding text is derived from his commentary on De anima book III treatise 1 chapters 1-3. According to Albert, the imagination accomplishes the second of four phases of abstraction by abstracting from the presence of the object perceived, whereas the fantasy's proper function consists in grasping the sensible object under its intentional aspects.

\section{Introducción}

Como casi todo en la Filosofía Medieval, también las discusiones sobre el ser y las funciones de la fantasía comienzan con Aristóteles. A pesar de la importancia innegable del Estagirita, en su De anima él presenta una serie de caracterizaciones, dispares en ocasiones $y$, en otras, en aparente contradicción. Pero, como la intención del presente escrito no es hacer una crítica de la obra aristotélica, no me detendré con sus planteamientos y haré un recorrido sumario de la postura del dominico Alberto Magno, quien desde luego fue un asiduo lector de los escritos de Aristóteles, y haré referencia a la así llamada Summa de homine y al comentario al De anima. Posteriormente se presentará una traducción parcial del libro III tratado 1 capítulos 1 a 3 de su comentario al De anima.

\footnotetext{
' La traducción que se presenta a continuación forma parte de una traducción íntegra del comentario al De anima de Alberto Magno que en la actualidad estoy preparando para su publicación en la "Colección de Pensamiento Medieval y Renacentista" de la editorial EUNSA. Agradezco al editor de la presente colección, Juan Cruz Cruz, por permitir la impresión parcial de la traducción.
} 
Alberto, al igual que en siglos anteriores Avicena y Averroes, piensa que la fantasía (phantasia) reside en el cerebro y que es parte constitutiva de aquello que él denomina 'sentido interior' (sensus interior $)^{2}$. Sin embargo, Alberto es consciente de la necesidad de distinguir la caracterización genérica de los sentidos interiores de sus funciones individuales. Por eso considera que el concepto de sentido interior puede ser entendido en un sentido amplio (large) y en un sentido estricto (stricte), distinción que él busca aclarar por medio de un análisis del significado del término 'fantasía' Cuando el sentido interior es entendido en su sentido amplio, entonces abarca las funciones de la imaginación, de la fantasía y de la estimación (imaginationem et phantasiam et aestimationem). En su sentido estricto, sin embargo, el sentido interior de la fantasía es descrito como aquel sentido que reúne, compone y descompone imágenes (imagines) $^{3}$. No sobra decir que esta diferenciación conceptual entre un significado amplio y uno estricto también aplica a la memoria y a la virtus cogitativa ${ }^{4}$.

Ahora bien, ¿qué implica tal diferenciación en el caso de la fantasía? Los sentidos amplio y estricto de 'sentido interior' parecen sugerir dos maneras de describirlo. (1) Cuando se habla de la fantasía en un sentido amplio, Alberto parece referirse a géneros de capacidades sensitivas interiores, y esto quiere decir que todo sentido interior es, de alguna manera, una fantasía en la medida en que opera con base en representaciones mentales individuales. (2) En el sentido estricto, el concepto de fantasía circunscribe sus funciones y actividades específicas, de las cuales habrá que hablar a continuación.

\footnotetext{
${ }^{2}$ En lo que sigue haré referencia principalmente a WOLFSON, H. A.: "The Internal Senses in Latin, Arabic, and Hebrew Philosophic Texts", Harvard Theological Review XXVIII (1935), pp. 69-133 y STENECK, N. H.: "Albert the Great on the Classification and Localization of the Internal Senses", Isis LXV (1974), pp. 193211.

${ }^{3}$ Véase Alberto Magno: Secunda Pars Summae de Creaturis, Opera Omnia vol. 35, August Borgnet (ed.), Parisiis: Vivès 1896, p. 331 a (q. 38 a. 1). En lo que sigue se referirá a esta obra como Summa de homine; así se conoce la segunda parte de la Summa de creaturis.

${ }^{4}$ Véase STENECK: op.cit. p. 202.
} 
La fantasía en el sentido estricto es un sentido interior. El criterio para establecer si se trata de una facultad cognitiva interior se deriva de la distinción aviceniana entre aprehender externamente y aprehender internamente. ${ }^{5} \mathrm{La}$ fantasía, entonces, y a diferencia de los sentidos exteriores, es apprehensivus deintus. Por ende, una potencia cognitiva es interior solamente cuando su funcionamiento adecuado no depende de la presencia espacio-temporal del objeto captado ${ }^{6}$. Al aplicar este criterio, Alberto distingue cinco sentidos interiores: la fantasía (phantasia), la imaginación (imaginatio), la aestimativa, la memoria y la reminiscencia ${ }^{7}$. Cabe anotar que la aplicación del criterio mencionado significa para Alberto que el sentido común no puede ser propiamente un sentido interior, ya que su objeto directo de aprehensión tiene que estar presente ${ }^{8}$. De esta manera, el sentido común es apprehensivus deforis $\mathrm{y}$, por ende, pertenece a la sensación exterior como ultimum sentiens.

En lo que respecta la teoría de la fantasía, es importante recalcar que Alberto distingue dos modalidades en que ésta se presenta: la imaginación por un lado y la fantasía en el sentido estricto por el otro. La distinción entre estas dos facultades remonta a los grados de abstracción a que refieren ${ }^{9}$. Ya Tomás de Aquino rechazaría tal duplicidad de los términos al decir que "a la retención y conservación de estas formas se ordena la fantasía o imaginación, que son idénticas" ${ }^{10}$. Alberto, no obstante, habla de una imaginación

${ }^{5}$ Cf. Avicena: Liber De Anima seu Sextus De Naturalibus, vol. 1, S. van Riet (ed). Louvain/Leiden: Éditions Orientalistes/Brill 1968, p. 83, 56-57 (1, 5).

${ }^{6}$ Cf. STENECK: op.cit. p. 198; también ALBERTO MAGNO: Summa de homine q. 42 a. 2 p. 361 a.

7 Cf. AnzUlewicz, H.: "Konzeptionen und Perspektiven der Sinneswahrnehmung im System Alberts des Grossen", Micrologus X (2002), p. 225.

${ }^{8}$ AlBERTO MAGNO: Summa de homine q. 42 a. 2 sol. p. 360 a: "[Vires] distinguuntur secundum diversificantur formae sensibiles in praesentia materiae [...]".

${ }^{9}$ Cf. Alberto Magno: De Anima, Opera Omnia, tomus VII, l, Clemens Stroick (ed.), Münster: Aschendorff 1968, pp. 101b-102b (Il, 3, 4). Esta distinción fue propuesta por AVICENA: De an. II, 2 pp. 114-119. Véase también Edward P. MAHONEY: "Sense, Intellect, and Imagination in Albert, Thomas, and Siger" en Norman Kretzmann et al. (eds.): The Cambridge History of Later Medieval Philosophy, Cambridge: University Press 1982, pp. 603.

${ }^{10}$ TOMÁS DE AQuino: Su. Theol. I q. 78 a. 4 c. 
que cumple su función específica en el contexto de los cuatro grados de abstracción, cuyo grado máximo constituye el conocimiento intelectivo ${ }^{11}$. En el primer grado de abstracción se abstrae netamente de la materialidad del objeto captado: "En el grado primero e inferior, la forma es abstraída y separada de la materia, pero ni de su presencia ni de sus apéndices. Esto lo hace la facultad que aprehende lo exterior, es decir la potencia sensitiva" 12 .

La imaginación, en cambio, se ocupa del segundo grado de abstracción al separar las especies sensibles "de la materia y de la presencia de la materia, pero no de los apéndices de la materia, o sea de las condiciones materiales" ${ }^{13}$. En el tercer grado de abstracción, sin embargo, no solamente se presenta una disminución de la materialidad respecto del objeto captado, sino que además se captan primordialmente las intenciones de los objetos materiales, es decir "ciertas intenciones que no son impresas en los sentidos", como lo son la sociabilidad del amigo, lo agradable de un banquete, etc ${ }^{14}$. De este grado de abstracción dice Alberto que es el "grado [...] más cercano al conocimiento y nunca se presenta sin la estimación y comparación" ${ }^{15}$. Solamente el cuarto grado de abstracción conlleva la adquisición de un conocimiento universal al aprehender "las quididades de las cosas desprovistas de todos los apéndices materiales" 16 .

De esta manera queda claro, y para resumir lo esencial de su postura, que para Alberto imaginatio y phantasia son sentidos interiores distintos debido a las diferentes funciones que cumplen con miras al proceso de abstracción. En este contexto es de especial interés la phantasia, la cual capta las intenciones de los objetos sensibles. Sobre este tema ya he escrito en otro lugar ${ }^{17}$. Sin embargo,

${ }^{11}$ Cf. Alberto Magno: De anima $\Pi$, 3, 4, pp. 101-102.

12 Ibid. p. 101, 68-71.

13 Ibid. p. 101, 72-74.

14 Ibid. P. 101, 91-92.

15 Ibid. p. 102, 8-10.

${ }^{16}$ Ibid. p. 102, 11-13.

17 Tellkamp, J. A.: "Percepción, intencionalidad y lenguaje en el aristotelismo del siglo XIII", Tópicos XXVIII (2005), pp. 303-325. 
vale la pena resaltar un aspecto importante: la phantasia es una facultad orgánica del cerebro, cuya función consiste en captar ciertos estados de cosas que no se encuentran fisicamente en el mundo y que, por tanto, no pueden ser captados por un sentido exterior o interior, ya que las intenciones no se presentan debido a un vinculo causal que media entre el objeto sensible y los sentidos. Así, por ejemplo, la enemistad natural del lobo no es un atributo esencial o accidental del lobo. El contenido intencional del lobo es más bien captado por un ser, una oveja por ejemplo, que le adscribe cognitivamente tal propiedad al lobo. En este sentido, la phantasia, que se da juntamente con la estimación y comparación, comparte rasgos que autores del siglo XIII, incluyendo Alberto Magno, atribuyen comúnmente a una facultad sensorial especial: la aestimativa o cogitativa.

De hecho, esta última posee la función de preparar los datos sensoriales de tal manera que un animal o ser humano pueda captar los rasgos intencionales de un objeto ${ }^{18}$. De esta manera y a diferencia de lo que sugiere el términc, la phantasia, pero no la imaginatio, no se dirige a imágenes sensoriales, ni tiene como objeto alguna copia pictórica de un objeto material, sino que exclusivamente capta los aspectos intencionales de los mismos.

${ }^{18}$ Alberto Magno: Summa de homine q. 39 a. 1, p. $337 \mathrm{a}$. 


\section{Alberto Magno: Sobre el alma (traducción)}

Tercer libro: Acerca de las facultades aprehensivas y motrices internas

Primer tratado: Sobre las facultades sensibles aprehensivas del alma

\section{Capítulo 1: Digresión que explica la intención del libro; sobre la imaginación}

En este libro III Sobre el alma queremos hablar certeramente sobre las restantes potencias del alma. La primera división de ellas es entre las potencias aprehensivas y las motrices, que difieren por su significado de las potencias activas y pasivas. Las diferencias entre las potencias fueron señaladas arriba, de manera que la potencia activa siempre guarda una semejanza consigo misma, ya que ella misma es acto y siempre es completa con miras a operar ${ }^{19}$. Y si alguna vez no operara, esto sería por un defecto de la cosa sobre la cual opera y no porque ella requiera adquirir algo que perfeccione su acción. La potencia pasiva, en cambio, no guarda semejanza consigo misma, porque a veces posee la forma y a veces no; pero cuando la adquiere por medio de la alteración, puede entonces realizar la acción, cuyo principio es la forma, que es adquirida por la misma alteración. Esta forma, sin embargo, a veces le es dada por medio de la generación, como dijimos arriba respecto de la potencia sensitiva $^{20}$. A veces, en cambio, es adquirida por medio de la alteración de la misma manera como la ciencia, que es la perfección del intelecto.

Las potencias aprehensivas son, entonces, generalmente potencias pasivas y sólo poseen un principio activo debido a la forma que se adquiere por medio de la aprehensión. Por eso se llaman aprehensivas .estas potencias. Éstas no se relacionan con toda el

\footnotetext{
19 Alberto Magno: De anima $\Pi, 3,1$.

${ }^{20}$ Alberto Magno: De anima II, 3, 3 .
} 
alma, sino sólo con el alma sensitiva e intelectiva. De éstas algunas son aprehensivas y operan por medio de las cosas exteriores; otras, sin embargo, son aprehensivas de tal manera que sus principios agentes son internos. Aquellas, cuyos principios agentes son exteriores, son las facultades sensitivas, de las cuales ya nos desembarazamos, en cuanto son facultades del alma. Aquellas, en cambio, que aprehenden interiormente, serán discutidas ahora. Uniremos todas estas partes, bien sean del alma sensitiva bien del alma racional, porque ciertos autores antiguos dijeron que todas ellas pertenecen a una cierta parte intelectiva, tal como se expondrá en lo siguiente $^{21}$. Para entender con mayor facilidad las teorías de los autores antiguos al respecto, queremos hablar de tres facultades, que enumeramos arriba, es decir la imaginativa, la estimativa y la fantasia 22 .

Decimos entonces que la imaginativa es una potencia aprehensiva, en la que se conservan las imágenes de las cosas sensibles ausentes. Esta imaginación abstrae en mayor grado que las facultades sensitivas, puesto que la facultad sensitiva sólo recibe la forma estando la cosa presente. Ésta, sin embargo, la conserva en ausencia de la cosa. Según Avicena y Algazel es, por eso, una potencia distinta del sentido común ${ }^{23}$. La bondad de esta facultad orgánica difiere de la bondad de la facultad sensitiva, porque la bondad de ésta está en la recepción y la bondad de aquella consiste en la retención $\mathrm{y}$ en la representación pura. Por esta razón vemos que existen muchos que disciernen sutilmente lo sensible, pero que no tienen una buena imaginación.

Con todo, quienes poseen una buena imaginación, se disponen a dos tipos de conocimientos. Uno es el matemático, porque estos hombres describen muy bien las figuras. La razón de ello está en que, aunque en el órgano de la imaginación se describan todos los objetos sensibles, los objetos sensibles mismos, sin embargo, son

\footnotetext{
${ }^{21}$ Alberto Magno: De anima III, $1,5$.

${ }^{22}$ Alberto Magno: De anima $\Pi$, 4, 7.

23 Avicena: De an. IV, 1, pp. 1-11; Algazel: Metaphysica, J.T. Muckle (ed.), Toronto 1933, p. 170, 1-4 (II, 4, 4).
} 
descritos cuando se unen a sus sujetos. Por eso sólo se puede imaginar un sonido cuando existe un objeto sonante en acto; y se puede imaginar un color cuando existe la cualidad de un objeto coloreado, y así respecto de los demás objetos sensibles. Por eso, lo que principalmente es descrito en estos objetos es la cuantidad y la figura. Por esta razón, quienes poseen los órganos de estas potencias en una composición pura y buena, imaginan de manera óptima. $Y$ cuando además poseen un intelecto sutil, entonces sobresalen en las disciplinas matemáticas, debido a la unión de un intelecto bueno con una imaginación buena.

Entonces, si estos hombres abstrajeran de los movimientos sensoriales y si estuviesen solitarios con frecuencia y si abstrajeran de la preocupación por la carne y de las delicias del cuerpo, se convertirian en profetas ${ }^{24}$. En efecto, el movimiento de muchos objetos sensibles impide, por su desorden, que se manifiesten en los hombres los efectos de los cuerpos celestes. De manera parecida, pues, la preocupación por la carne, las delicias, las angustias y muchos actos mundanos ocupan el alma de tal manera que ésta no pueda percibir las impresiones de los cuerpos celestes, ya que el alma, debido a la unión sustancial con sus potencias, tiene tal vínculo con sus facultades que, cuando quiere realizar una operación con cualquier potencia, no pone atención a otra. El indicio de ello está en que quien piensa intensamente,' no ve lo que tiene frente a sus ojos. De manera parecida ocurre que el alma, ocupada con las cosas exteriores, no se percata de los movimientos y de las impresiones de los cuerpos celestes, que se producen en su cuerpo. Prescindiendo de estas ocupaciones, percibe tales impresiones y provee imágenes de ellas, porque le es connatural conocer todo cuanto conoce por medio de las imágenes corporales. En tales impresiones de los cuerpos celestes radican los sueños que significan los hechos futuros. De qué manera las impresiones tanto de los movimientos celestes como de las inteligencias, que son motores, llegan hasta las almas animales,

${ }^{24}$ La conexión entre imaginación y profecia es un reflejo de AVICENA: De an. IV, 2, p. 19, 61-62. 
será mostrado en la Metafisica ${ }^{25}$. Pero aquí basta decir que no es necesario que el órgano de la imaginación no sea completamente idéntico con el órgano del sentido común, sino que sea diferente según su ser, aunque acaso sea idéntico en su sustancia. Esto se ampliará más adelante ${ }^{26}$.

\section{Capítulo 2: Digresión que explica lo que corresponde a la estimativa}

La potencia, que se llama estimativa, difiere de la imaginación por la especie aprehendida, puesto que la estimativa, como se estableció anteriormente, obtiene las intenciones que son descritas en las facultades sensitivas ${ }^{27}$. Tampoco se puede decir, en relación con lo que establecimos arriba respecto de los objetos percibidos accidentales, que ésta sea la función de la facultad sensitiva ${ }^{28}$. Razón: no se conocería nunca al hijo de Dión, si no se tuviera el conocimiento de la filiación que se encuentra en éste; tampoco el lobo se compadecería de su prole, si no tuviese un conocimiento de este individuo $y$ que este individuo es su prole. Es entonces necesario que exista una facultad del alma que produzca estas intenciones, y ésta no puede ser la imaginación ni algo enteramente separada de ella. Que no se trata de la imaginación es obvio, porque de la sola imagen de la cosa no se siguen el movimiento ni los afectos de la misericordia, tristeza, fuga o persecución. De la estimación, no obstante, se siguen inmediatamente cualquiera de estos movimientos o afectos. Sin embargo, esta facultad tampoco puede estar enteramente separada de la imaginación, ya que estas intenciones no se captan respecto de sus aspectos comunes y universales, sino más bien porque están en esta o aquella imaginación, sin conjetura acerca de lo común. Es entonces nẹcesario decir que, así como el intelecto práctico se relaciona con el especulativo, así se relaciona la estimativa con la imaginación. Por

${ }^{25}$ Alberto Magno: Metaphysica, Opera Omnia, tomus XV, 2, Bernhard Geyer (ed.), Münster: Aschendorff 1964, pp. 506-510 (XI, 2, 19-24).

${ }^{26}$ AlBerto Magno: De anima III, $1,3$.

${ }^{27}$ AlBerto MAGNo: De anima II, 4, 7.

${ }^{28}$ Alberto MAGNo: De anima II, 3, 5. 
eso, esta facultad no es enteramente aprehensiva, sino que es también motriz en cuanto determina aquello hacia lo cual el animal debe moverse y aquello de que debe huir. Por eso dijeron algunos filósofós que se trata de la opinión, lo cual no es plausible, porque la opinión racional del alma es un cierto hábito. La estimación, sin embargo, trata de todo aquello que pertenece a las facultades sensitivas, como ya señalamos ${ }^{29}$. Arriba dijimos, en efecto, que todos los seres sensitivos poseen al menos un movimiento de dilatación y otro de encogimiento ${ }^{30}$. Y puesto que ellos se mueven de alguna manera hacia el alimento, es necesario que tengan en sí la imaginàción del alimento. Pero la imaginación sola no mueve, como ya se ha dicho; es entonces necesario que todos estos animales tengan tal estimación, por medio de la cual sean movidos.

Todo animal; que tiene uno o varios sentidos exteriores, posee estos tres sentidos interiores, es decir el sentido común, la imaginación y la estimativa. Por eso dijimos arriba que todo animal, que posee facultades sensitivas, desea el alimento ${ }^{31}$. También todo animal, que tiene deseo, no posee la imaginación y la estimación, la cual difiere de la imaginación, no según la sustancia, sino según el ser, como ya dijimos ${ }^{32}$. La estimativa es, con todo, más activa que la imaginativa, puesto que la obtención de las intenciones es una cierta acción y es más perfecta que sólo reflejar las imágenes, como si dijéramos que un espejo animado reflejara las imágenes impresas en él.

Todas las facultades del alma, no obstante, son activas de alguna manera, porque todas realizan alguna función vital, como mostramos arriba, donde hablamos de la definición del alma en cuanto a su sustancia $^{33}$. Aunque la estimativa sea activa en mayor grado que la imaginativa, tiene, sin embargo, la propiedad de una potencia pasiva

${ }^{29}$ Alberto Magno: De anima I, 2, 12.

${ }^{30}$ Alberto MAGNo: De anima I, 2, 12.

${ }^{31}$ AlBerto Magno: De anima II, 1, 10.

${ }^{32}$ AlBerto MAGNO: De anima II, $1,11$.

${ }^{33}$ Alberto Magno: De anima II, $1,1$. 
en la medida en que no opera por sí misma, sino por la intención, que obtiene de la forma adquirida.

En este punto hay que advertir que en el hombre ocasionalmente se une esta facultad, así como las demás, con la razón, y entonces es apoyada por la razón y es compelida a imitar o huir del objeto de la estimativa. Debido a que en el hombre ésta se asemeja a la opinión, algunos filósofos, como Platón, aseguraron que la estimativa es lo mismo que la opinión y que sólo difiere en los hombres y en los animales brutos, porque en los animales es más oscurecida y en los hombres menos. Pero esto es falso, porque la opinión trata de lo común en cuanto se encuentra en muchas cosas; la estimación, sin embargo, en cuanto es tal, no se aparta del individuo en cuanto tal. Por eso en el hombre, cuando es ayudada por la razón, sólo es ayudada en cuanto trata de este o aquel individuo; y en este caso obtiene el nombre propio de estimación. En cambio, si se produjera una concepción similar de muchas cosas particulares, captadas según una intención encontrada en ellas, ya no se trataría de la estimación, sino del conocimiento por experiencia, que pertenece a la razón. Sin embargo, las facultades sensitivas y la estimación subyacen a este conocimiento. Dado que la facultad unida de esta manera es la imaginación, se desprende que su órgano o bien es idéntico al órgano de la imaginación o bien está en vecindad de un órgano de otras facultades. Sustancialmente tiene una existencia idéntica y según su ser posee disposiciones diferentes, como dijimos arriba ${ }^{34}$.

\section{Capitulo 3: Digresión que explica la naturaleza de la fantasia}

Después de lo anterior y al examinar la fantasía, decimos que ella es una potencia que compone las imágenes con intenciones y las intenciones con imágenes y las imágenes con imágenes y las intenciones con intenciones, respecto de una doble finalidad que se encuentra en las cosas particulares. Una finalidad consiste en el conocimiento mayor de las cosas particulares, que se puede alcanzar en el alma sensitiva. Su finalidad consiste en llegar a la proposición

34 En el capitulo anterior. 
que esto es aquello y que lo otro es otro. $\mathrm{Y}$ esto es así respecto de todo aquello de que se puede proferir una proposición en el modo de una afirmación o negación. La segunda finalidad consiste en la operación, cuya intención parte de estas cosas particulares, de la misma manera como la operación es, en los seres racionales, la finalidad del arte. Este tipo de conocimiento surge expresamente en muchos animales, porque vemos que éstos lo eligen y que otros parecen casi rechazarlo. Con miras a la elección, entonces, y al rechazo, se requieren proposiciones y decisiones. Por eso dijeron muchos que la fantasía pertenece a la razón. Sin embargo, no es nuestra intención decir que existe una verdadera elección en el alma sensitiva, pero manifiestamente vemos algo parecido a una elección en ciertos animales brutos, y en algunos más que en otros. También vemos que ellos hacen albergues al modo de un arte y se proveen de alimentos para un tiempo largo. El principio de estas operaciones necesariamente es una potencia del alma sensitiva. Esto sólo es posible debido a esta facultad que compone y divide las imágenes por el modo arriba mencionado. En efecto, no vemos estas obras en todos los animales que tienen imaginación y estimación, sino en algunos animales más perfectos. Es, por tanto, necesario que la fantasía por algo se distinga de la imaginación y de la estimación. Aunque todas estas potencias sean potencias pasivas del alma y aunque sean alteradas por las formas individuales - que son los principios del conocimiento sensorial y parecen ser formas idénticas - el modo de la alteración, sin embargo, no es el mismo, sino que se da de acuerdo con distintos grados de abstracción. Por esta razón, en el fondo tampoco son idénticas las potencias mismas; pero, como dijimos arriba respecto del sentido común, parece que todo aspecto formal sensible de la facultad reside en la fantasia ${ }^{35}$. Aqui existe una diferencia material, en la medida en que su movimiento comienza en el órgano de una facultad o en el órgano de otra facultad. Y de esta manera parece que todos estos sentidos interiores comparten una esencialidad y sustancia común. Sin embargo, son diferentes en cuanto a su ser material en las distintas partes del cerebro, donde estas potencias son organizadas y donde son completamente orgánicas. Y esta es la razón por la que Aristóteles hizo referencia a

${ }^{35}$ Alberto Magno: De anima II, 4, 11. 
estas facultades como si fueran idénticas y equivocamente utilizó el nombre de una facultad en vez del nombre de otra, a pesar de existir una diferencia sutil. En este contexto son distintas y se relacionan de manera distinta.

Con todo, cuando estas potencias están unidas a la razón, como en el caso del hombre, es necesario revelar que éstas reciben de la razón su ordenamiento y la dirección para producir y operar. Y puesto que la razón se diversifica respecto de aquello sobre que raciocina, por eso las operaciones de las fantasias se multiplican considerablemente. Cuando éstas no se presentan con la razón, entonces son únicamente dirigidas por el instinto natural. Y puesto que la naturaleza posee un solo modo en algo de una sola especie, se sigue que las operaciones de la fantasía tienen un solo modo en los seres irracionales, que tienen una sola especie. Por eso, todas las golondrinas hacen el nido de un solo modo y por eso todas las hormigas se proveen de alimento de un solo modo. Lo mismo aplica a los demás animales de acuerdo con el discernimiento de la fantasía en los animales que operan por instinto natural. El hombre, en cambio, no opera de esta manera respecto de los diferentes principios operativos, los cuales busca por medio de la razón.

$Y$ algunos filósofos sobresalientes en filosofia natural dijeron que en los animales brutos estas facultades operan en mayor grado por naturaleza que por sí mismas ${ }^{36}$. En el hombre, en cambio, operan por si mismas en mayor grado que por otra cosa, porque en el hombre la naturaleza las apoya instrumentalmente. En los animales brutos, sin embargo, la naturaleza las mueve en mayor grado que por movimiento propio. Por cierto, se trata de la facultad, que en la mayoría de los casos obstaculiza el intelecto, ya que ocupa demasiado al alma debido a la composición y división de lo imaginado $\mathrm{y}$ de las intenciones, de las cuales posee una gran cantidad, porque no sólo puede componer lo que recibe de los

${ }^{36}$ Averroes: Commentarium Magnum In Aristotelis De Anima Libros, Stuart Crawford, F. (ed.), Cambridge (Mass.): Medieval Academy of America 1953, p. 530, 32-40 (III, 57). NEMESIO DE EMESA: De Natura Hominis, traduction de Burgundio de Pise, Gérard Verbeke y J.R. Moncho (eds.), Leiden: Brill 1975, pp. 23-50 (cap. 2). 
sentidos, sino que también puede formar lo que es similar. Y puesto que las concepciones del intelecto frecuentemente no guardan semejanza con las imágenes y con lo producido por la fantasía, por eso, cuando provee los conceptos de las imágenes e intenciones, se genera frecuentemente el engaño y el error, sobre todo cuando en el intelecto se imprime algo de los cuerpos celestes o de algo divino. Esta es la razón por la que los sueños proféticos del futuro, que se unen principalmente con las imágenes, producen ilusiones $y$ engaños. Pero cuando la fantasía añade imágenes e intenciones coherentes a las concepciones del intelecto,. entonces las composiciones requieren adicionalmente de la interpretación de las imágenes e intenciones, porque las imágenes e intenciones sensitivas sólo corresponden metafóricamente a los conceptos divinos y celestes. De esto, sin embargo, hablaremos en la ciencia Sobre el sueño y la vigilia ${ }^{37}$.

Ciertamente existen muchos animales que no poseen esta potencia debido a un defecto o por la disminución del cerebro en ellos. Todo su cerebro se distingue un poco de la naturaleza medulosa y líquida, en que se da la percepción y la imaginación tenue. Por eso no se depuran los espíritus de estos animales y el cerebro de ellos no es apropiado para realizar las operaciones animales perfectas.

${ }^{37}$ ALBERTo MAGno: De somno et vigilia III. 
Copyright of Tópicos. Revista de Filosofía is the property of Universidad Panamericana and its content may not be copied or emailed to multiple sites or posted to a listserv without the copyright holder's express written permission. However, users may print, download, or email articles for individual use. 